\title{
Transatlantica
}

Revue d'études américaines. American Studies Journal

\section{Colloque « Regards croisés sur le 11 septembre - Perspectives on 9/11»}

Aix-en-Provence, Université de Provence, 7-9 octobre 2010

\section{Yves Davo}

\section{OpenEdition}

\section{Journals}

\section{Édition électronique}

URL : https://journals.openedition.org/transatlantica/5075

DOI : 10.4000/transatlantica. 5075

ISSN : 1765-2766

Éditeur

Association française d'Etudes Américaines (AFEA)

Référence électronique

Yves Davo, «Colloque « Regards croisés sur le 11 septembre - Perspectives on 9/11 » », Transatlantica [En ligne], 2 | 2010, mis en ligne le 12 avril 2011, consulté le 02 février 2023. URL : http://

journals.openedition.org/transatlantica/5075; DOI : https://doi.org/10.4000/transatlantica.5075

Ce document a été généré automatiquement le 2 février 2023.

Creative Commons - Attribution - Pas d'Utilisation Commerciale - Pas de Modification 4.0 International - CC BY-NC-ND 4.0

https://creativecommons.org/licenses/by-nc-nd/4.0/ 


\title{
Colloque « Regards croisés sur le 11 septembre - Perspectives on 9/11 »
}

\author{
Aix-en-Provence, Université de Provence, 7-9 octobre 2010
}

Yves Davo

1 Le colloque de ce mois d'octobre, co-organisé par le Laboratoire d'Études et de Recherche sur le Monde Anglophone (LERMA) ${ }^{1}$ et l'Équipe de Recherche sur l'Imaginaire Contemporain, la Littérature, les Images et les Nouvelles Textualités (ERIC LINT), ${ }^{2}$ fait suite à la journée d'études du 5 juin 2009 qui avait posé les jalons d'une recherche tournée vers la littérature anglophone post-11 septembre. De par sa nature très internationale et son partenariat avec l'Université du Québec à Montréal, ce colloque a largement ouvert les perspectives vers d'autres littératures, d'autres réflexions politiques et institutionnelles et d'autres champs culturels, dans une volonté toujours affirmée de croiser les regards sur l'impact et les répercussions des attentats du 11 septembre 2001.

2 En poussant plus avant les interprétations d'œuvres majeures sur la question, mettant ainsi à jour leur foisonnement (les œuvres de Paul Auster, Don DeLillo, Siri Hustvedt, Jay McInerney, Joseph O'Neill, Joyce Carol Oates, Thomas Pynchon, Jonathan Safran Foer, John Updike ou encore Ian McEwan ou Patrick McGrath ont été abordées), ${ }^{3}$ les participants spécialistes de littérature anglophone ont pu dresser, devant un auditoire fourni et attentif à ce nouvel objet d'étude universitaire, un panorama très complet des différentes questions posées par ces attentats à la fiction. Le " 11 septembre » est-il devenu un genre en soi ? Quelle place donner à l'événement réel dans la fiction, à l'expérience intime dans le récit collectif? Comment mettre en mots les maux du trauma?

3 Dans cette perspective de questionnement, l'ouverture vers d'autres esthétiques a su élargir un débat déjà riche en analyses. Arts plastiques et hypermédiatiques, littérature dessinée, musique et mouvement hip-hop, cinéma indépendant - ces autres formes d'expression ont eu une place de choix durant ces trois jours de colloque, révélant peut-être l'événement dans sa difficulté à être représenté. Pourtant, à travers ces différents espaces de médiatisation, la réponse au défi de l'innommable a pris la forme 
du «contre-récit» dont une figure est apparue de manière récurrente, celle de la mémoire et du témoignage comme vecteur de mémorialisation, comme l'ont montré deux interventions dans leurs approches muséologique et cathartique du souvenir. De même, une analyse des récits de l'Autre - arabo-américain, algérien ou yéménite - a su rendre compte des approches hétérodoxes de projets fictionnels issus d'une littérature postcoloniale se saisissant des problèmes de légitimité, d'appropriation, de censure pour recréer une lecture plus oblique et symbolique des enjeux culturels globalisés.

4 Hors du champ de la fiction, le 11 septembre a aussi donné lieu à plusieurs présentations revenant sur la portée historique extraordinaire de l'événement, ouvrant la voie à des crises militaires et sécuritaires, politiques et institutionnelles, rhétoriques et patriotiques. En revenant sur ces problématiques de sécurité nationale et internationale, de libertés publiques et individuelles, qui ont envahi l'espace politique états-unien dès le jour des attentats, ces interventions ont su démontrer le retentissement profond du 11 septembre au plus haut niveau des institutions américaines et analyser les différentes réactions du pouvoir ainsi que des médias, l'attitude des grands partis face à la dérive de la branche exécutive, les conséquences et les défis à relever pour ces institutions.

$5 \mathrm{Au}$ gré de ces multiples analyses, un témoignage est venu donner un regard tout particulier sur l'événement vécu in situ, celui de Julia Frey, Professeur émérite à l'Université du Colorado, écrivain et épouse de Ronald Sukenick, tous deux témoins visuels des attentats puisqu'habitant à l'époque face aux tours jumelles du World Trade Center. Le récit qu'a réalisé Julia Frey de l'expérience du choc, de l'impact des avions à l'effondrement des tours, de la fuite panique aux jours de solidarité qui ont suivi, a très vite débordé sur un émouvant hommage à son mari, héraut de l'autofiction américaine, qui s'est éteint en 2004, non sans avoir terminé son propre récit du 11 septembre, Last Fall. ${ }^{4}$

6 En tant que co-organisatrice de l'événement, l'équipe Eric Lint de l'Université du Québec à Montréal est venue présenter son «Lower Manhattan Project». Bertrand Gervais, directeur du centre de recherches et initiateur du projet, a ainsi expliqué en séance plénière le but de ce site internet ${ }^{5}$ et son mode de fonctionnement : banque de données en ligne recensant de manière exhaustive et très précise tout document traitant du 11 septembre, le LMP offre en outre des pistes de recherche, des articles ou encore des suggestions de lecture dans le but d'aider l'internaute intéressé par le sujet. Bertrand Gervais et son équipe ont ainsi fait une démonstration très convaincante des possibilités de ce site, en insistant sur le caractère participatif des données, ouvertes à toutes les bonnes volontés.

7 Enfin, en invitant Kristiaan Versluys, Professeur à l'Université de Gand et pionnier des études sur la littérature post-11 septembre, le Laboratoire d'Études et de Recherche sur le Monde Anglophone (LERMA) de l'Université de Provence a permis aux chercheurs présents de revenir sur les différentes formes de récit de l'événement comme sur autant de tentatives de dire l'indicible. Auteur d'un ouvrage de référence sur le 11 septembre dans la littérature, paru en 2009 chez Columbia University Press, ${ }^{6}$ Kristiaan Versluys a ainsi dédié sa conférence plénière à une réflexion sur une écriture du trauma dans sa spécificité post-11 septembre. Cette conférence est venue clore trois journées de réflexion fort enrichissantes sur les répercussions, les représentations, les 
recréations des attentats du 11 septembre 2001 dans les différentes aires du monde littéraire, artistique, politique et culturel.

\section{ANNEXES}

Programme du colloque :

http ://gsite.univ-provence.fr/gsite/document.php ?pagendx =11039\&project =lerma Site du Lerma :

http ://gsite.univ-provence.fr/gsite/document.php ?pagendx =1516\&project =lerma Site de l'Eric Lint :

http ://ericlint.uqam.ca/

Site du Lower Manhattan Project :

http ://www.lmp.uqam.ca

\section{NOTES}

1. http://gsite.univ-provence.fr/gsite/document.php?pagendx=1516\&project=lerma

2. http://ericlint.uqam.ca/

3. Le programme détaillé du colloque est disponible sur : http://gsite.univ-provence.fr/gsite/ document.php?pagendx=11039\&project=lerma

4. Sukenick, Ronald, Last Fall, FC2, 2005.

5. http://www.lmp.uqam.ca

6. Versluys, Kristiaan, Out of the Blue : September 11 and the novel, Columbia University Press, 2009.

INDEX

Thèmes : Actualité de la recherche

\section{AUTEUR}

YVES DAVO

Université Michel de Montaigne Bordeaux 3 